\title{
THE SOCIAL LIFE OF EMOTIVE INTERJEC- TIONS IN SPOKEN BRITISH ENGLISH
}

\author{
Ulrike Stange \\ Johannes Gutenberg-Universität, Mainz \\ stangeu@uni-mainz.de
}

\begin{abstract}
This paper explores the discursive use of selected emotive interjections (Ow!, Ouch!; Ugh!, Yuck!; Whoops!, Whoopsadaisy!) in spoken British English. The data (drawn from the Spoken BNC2014) are coded for age, gender, social grade and type of dyad to identify potential factors governing the discursive use of these interjections. Based on 140 relevant tokens, the results suggest that: 1) The individual interjections vary significantly regarding how frequently they are found in discursive uses $\left(p<0.001^{* *}\right)$. 2) Whoopsadaisy! is not attested in discursive uses. 3) Young female speakers behave differently from the other speaker groups in that they use emotive interjections discursively significantly more frequently $\left(p=0.006^{* *}\right)$. 4) Female speakers in general use a wider range of interjections discursively: Ow! and Whoops! in discursive uses were absent from male speech. 5) Socio-economic status is irrelevant, as is 6) type of speaker dyad. Thus, the social life of emotive interjections is mainly influenced by speaker gender, and if the speakers are female, also by their age.
\end{abstract}

\section{Introduction}

This paper explores the discursive use of emotive interjections in presentday spoken British English. The term discursive use, introduced by Goddard (2014b: 55), describes the production of interjections in "situations in which the stimulus is not something in the immediate context, either a physicalsensory stimulus or a human action or behavior, but rather something the speaker is thinking about." This kind of use is found in Examples (1) and (2) just below: 
(1) UnkSp1: It's like one guy down in Wales when I went down there last time. He's fucking stood there, he's got the sneezes and he's whaaa whaaa whaaa in his fucking beer. He's going (pause) oh that'll deter people from fucking nicking it. Every two minutes.

UnkSp2: Ugh!

Mick: $\quad$ Sneezing in his fucking beer. Ugh.

[BNC1990 KDA: 3629, 3632] ${ }^{1}$

(2) Peter: When I got off the bus she was at Hackney Cen- Central with all her friends.

Muham.: Ow! So you went and pulled her to one side.

Peter: No I didn't actually I just, ignored her and went on.

[BNC1990 KPT 1247]

Drawing on the Spoken BNC2014, this study focuses on interjections of pain (Ow!, Ouch!), of disgust (Ugh!, Yuck!) and spill cries ${ }^{2}$ (Whoops!, Whoopsadaisy!). It will identify interjection-specific patterns with respect to frequency of discursive use as well as emerging patterns based on speaker age and gender, socioeconomic status as well as type of dyad (male - male, male - female, etc.).

This paper is structured as follows: the next section introduces the core concepts related to the emotive interjections under investigation and sketches the differences between various types of use, paying special attention to discursive use. Section 3 outlines what we know from previous studies and identifies research lacunae. Section 4 lists the research questions and presents the database and the method used to find the corresponding answers. The results are discussed in the subsequent section, and the article concludes with a summary of the main findings as well as suggestions for further research.

\section{Emotive interjections and their discursive use}

Emotive interjections "express the speaker's state with respect to the emotions and sensations [he has] at the time" (Ameka 1992: 113). They can express a large variety of emotions and feelings: pain (Ow!), disgust (Yuck!), surprise (Wow!), joy (Whoopee!), disapproval (Tut-tut!), etc. Depending on their context of use, we find a) immediate, stimulus-bound uses, b) didactic uses, c) ironic and d) discursive uses (cf. Goddard 2014b: 54). In immediate uses, emotive interjections have also been referred to as interjections proper (Stange 2016a: 20) because they are often produced apparently involuntarily in response to a given stimulus (viz. pain, a mishap, a revolting sight, etc.). Example (3) below illustrates the stimulus-bound use of an interjection of pain.

(3) Ow my toe hurt. It keeps going through these pangs.

[SRTU: 362$]^{3}$ 
In didactic uses (Example 4), the emotive interjection is used deliberately to instruct (usually) the child about what is disgusting or causes pain, etc. (see also Goddard 2014a: 90).

(4) Yuck, you've got to get that mess off my finger, please. Yuck.

[SUC7: 428]

Ironic uses of emotive interjections express insincerely the standard meaning of the interjection in question. In Example 5 below, Wow! is used to pretend delight at the prospect of winning the "star prize".

(5) Paul: There's a star prize for the (unclear) [...]

Ruth: $\quad$ And the star prize is the whole of three Ferrero Rocher.

Joy: (laugh)

Michael: Wow!

[BNC1990 KD0: 5983]

Last, discursive uses are not stimulus-bound per se, rather the speaker is thinking about something that causes him to produce an emotive interjection (cf. Goddard 2014b: 55). Importantly, "[...] discursive uses of interjections can be understood as relying on a simple analogical transposition" in that "the speaker appeals to typical situations of when [they use this interjection] as a way of indicating the quality of [their] own current feeling" (Goddard 2014a: 90). That is, discursive uses require the speaker's understanding of how immediate uses work to use the interjection appropriately (cf. Goffman 1978: 806, Goddard 2014b). In Example (6) below it is debatable, whether the incident can really be downplayed to an "oops" but the fact remains that the mishap is commented upon by the interlocutor with a spill cry. The interjection thus functions as a response to the immediately preceding discourse.

(6) S0033: I was playing like Playstation games at like two in the morning, and I had my balcony window open and shouting and screaming as you do, and they just come up and started going mental to me cos I was waking up the entire camp-

S0018: Oops

S0033: Campus

[SJTT: 375$]$

In this paper, I will focus on the discursive use of emotive interjections. Whenever this use has been discussed previously, it was with reference to expressions of disgust (Wierzbicka 1992, Goddard 2014a, b). While it makes sense to assume that discursive uses work with other emotive interjections, too (as in example 6 above), the discursive use of phatic, conative (Example 7) or cognitive (Example 8) interjections seems extremely odd (cf. Stange 2016a: 43): 
(7) A: God, these kids were such a pain. I told them to be quiet, but they just wouldn't shut up.

B: ?? Shh!

(8) A: I really had no clue how to do my maths homework, so annoying! But my dad helped me and all and then finally the penny dropped.

B: ?? Aha!

In contrast to emotive interjections, phatic and conative interjections require an addressee: phatic interjections like $\mathrm{mhm}$ or $\mathrm{uh}$ huh function as backchannelling devices in ongoing conversation and signal that attention is paid to what is being said. Conative interjections require a reaction on part of the addressee: Shh! - 'be quiet' or Psst! - 'come to me so I can talk to you confidentially' (see also Wilkins 1992: 137, Ameka 1992: 113). Cognitive interjections like Ah! or Aha!, then, express a change in the speaker's state of mind with respect to what they know or understand, and they can be used in isolation or in conversation.

Having said this, it is because of their functions that these interjections are unlikely to be used discursively. Intuitively, it does not sound natural to produce Shh! in response to listening to a complaint about noise (Example 7), or to exclaim Aha! when it is someone else who is or was experiencing a light bulb moment (Example 8). Similarly, phatic interjections are used in response to what is being said to signal alertness on part of the speaker, so there is always a stimulus-bound use if you will. In short, phatic, conative and cognitive interjections only work with immediate, stimulus-bound uses (and in reported speech, of course), while emotive interjections also allow for deliberate uses in the absence of a (physical) stimulus. In these discursive uses, " $t]$ he interjection is being used to express the speaker's (purported) reaction" (Goddard 2014b: 55).

Incidentally, the discursive use of interjections has already been discussed briefly by Goffman (1978), albeit without this specific terminology. There is obviously a difference in the use of emotive interjections depending on whether the speaker uses them spontaneously, and there is no intended addressee, and on whether the speaker is engaged in conversation when they use them (cf. Goffman 1978: 805). Goffman further specifies:

If these responses are to be seen as ritualized expressions [...] then there is reason to expect that such cries will be used [...] in response to a VERBALLY PRESENTED review of something settled long ago, at a place quite removed. (Goffman 1978: 805)

Goffman (1978: 805) provides several relevant examples, e.g. the utterance of Ouch! in response to learning the price of a bill. Interestingly, emotive interjections can also be used on behalf of someone else: 
Indeed, response cries are often employed thrice-removed from the crisis to which they are supposed to be a blurted response: [...] we utter a response cry [...] out of sympathetic identification and as a sign that we are fully following [the] exposition. In fact, we may offer a response cry when [the interlocutor] recounts something that happened to someone ELSE. (Goffman 1978: 805)

These discursive uses are thus special because 1) they are produced in the absence of a physical stimulus, 2) they occur in on-going conversation, and because 3) they can be used to express the speaker's emotion, the interlocutor's and even that of a third party.

\section{Previous Studies}

Interjections have been the focus of linguistic research for the past three decades. Most notably, Ameka (1992), Wierzbicka (1992), Wilkins (1992), Nübling $(2001,2004)$ and Stange $(2009,2016 a)$ have contributed most of what we know about interjections. With respect to the discursive use of emotive interjections, however, there is still a research lacuna. Goddard (2014a, b), Goffman (1978) and Wierzbicka (1992) have commented on this function on interjections, and it is mentioned in passing in Stange (2016a) because it was attested in the corpus data. Table 1 below shows that the discursive use was most frequently found with interjections of disgust (Ugh!, Yuck!).

In fact, both Goddard (2014a, b) and Wierzbicka (1992) have commented on the discursive use of interjections in relation to expressions of disgust. In this respect, Wierzbicka (1992: 168) noted that Yuck! "would be unlikely to be used in this way" (that is, by just "perceiving 'disgusting' thoughts in one's head", Wierzbicka 1992: 169), while it is fine to use in response to a nonphysical stimulus. The example she provides is that of a student who is given an assignment they dislike (Wierzbicka 1992: 167). I would subsume both uses under discursive uses, as they both are responses to something abstract (still, in a way, both the thought and the assignment act as stimuli).

\begin{tabular}{|l|l|l|l|r|}
\hline & & \multicolumn{3}{|c|}{ discursive uses } \\
\hline interjection & $\begin{array}{l}\text { absolute } \\
\text { frequency }\end{array}$ & $\begin{array}{l}\text { absolute } \\
\text { frequency }\end{array}$ & $\begin{array}{l}\text { frequency } \\
\text { pmw }\end{array}$ & $\begin{array}{l}\text { percentage of } \\
\text { all uses }\end{array}$ \\
\hline Ow! & 50 & 3 & 0.71 & 6 \\
\hline Ouch! & 13 & 1 & 0.24 & 8 \\
\hline Whoops! & 56 & 0 & 0 & 0 \\
\hline Whoopsadaisy! & 0 & 0 & 0 & 0 \\
\hline Yuck! & 22 & 5 & 1.18 & 23 \\
\hline Ugh! & 147 & 30 & 7.09 & 20.4 \\
\hline
\end{tabular}

Table 1: Discursive uses of emotive interjections (Spoken BNC1994, adult-adult conversations only, based on Stange 2016a) 
To date, the knowledge pertaining to the discursive use of interjections is very superficial because it is mainly based on introspection and casual observation as opposed to a thorough empirical analysis. Also, the subset used in Stange's (2016a) study was quite small (4.2 million words), which is problematic if the phenomenon in question is rare to begin with. What is thus needed is a detailed investigation of this specific function of emotive interjections in a much larger data set. In this regard, it is important to note that Goddard calls into questions the suitability of corpora to reflect the use of interjections in everyday life: "Immediate uses of interjections of disgust, pain, and sensual pleasure, for example, are likely to be underrepresented in corpora, while discursive uses are likely to be overrepresented" (Goddard 2014: 56). There is, however, no relevant alternative to explore these lexical items in natural speech on a large scale. Thus, we must make do with the corpora available, despite potential drawbacks.

\section{Case Study}

\subsection{Research Questions}

The study will focus on interjections of pain (Ow!, Ouch!), disgust (Ugh!, Yuck!) and spill cries (Whoops!, Whoopsadaisy!). Drawing on the BNC2014, the study aims at providing a picture of how these interjections are used discursively in natural conversation. The data are coded for age, gender and socio-economic status of the speakers recorded, so it will be possible to detect potential differences in how they use emotive interjections depending on these social variables. The data will also be coded for type of dyad (male-male, male-female, female-female, female-male) and topic to see whether there are differences depending on the kind of interaction between speakers. The study will show which interjections are used most frequently discursively by what kind of speaker in what type of interaction. Shedding more light on the discursive use of interjections in natural conversation will help us understand better what their function in discourse is and will provide further evidence for the claim that interjections are not peripheral to language (cf. Norrick 2011) but a central element.

\subsection{Database \& Method}

The corpus used for the present study is the spoken component of the BNC2014 (Love et al. 2017). It contains a total of 11,422,617 million words produced by 672 speakers in 1,251 natural conversations between friends and family members. The conversations were recorded between 2012 and 2016 in informal settings, so they reflect modern British English usage. Among other features, the speakers are coded for age, gender and socio-economic status. See the manual for more details on the data collection and the make-up of the corpus (Love, Hawtin \& Hardie 2017). ${ }^{4}$ 
Table 2 below provides an overview of the subset sizes in the Spoken $B C N 2014$. Unfortunately, the data are heavily skewed in that most words were produced by young female speakers (especially with social grade $\mathrm{AB}^{5}$ ). They account for 38.2 per cent of the data (all social grades), while old male speakers contributed only 17.5 per cent. Furthermore, with merely 15.3 per cent of the data, $\mathrm{C} 1 / \mathrm{C} 2$ speakers are severely underrepresented. The split into the two age groups $0-39$ and $40+$ is motivated by similar divisions in previous research (e.g. Rosenbach 2003 and Stange 2016b), and considering the number of tokens in each cell, a more fine-grained division would have led to very low numbers in individual cells and even empty cells. This is also the reason why the social grades were combined into $\mathrm{AB}, \mathrm{C} 1 / \mathrm{C} 2$ and $\mathrm{DE}$.

In the results section, all frequencies will be displayed as normalised frequencies per million words ( $\mathrm{pmw}$ ) to allow for comparison between the different speaker groups.

\begin{tabular}{|l|l|l|l|l|l|}
\hline $\begin{array}{l}\text { social } \\
\text { grade }\end{array}$ & $\begin{array}{l}\text { female } \\
\text { speaker } \\
0-39\end{array}$ & $\begin{array}{l}\text { female } \\
\text { speaker 40+ }\end{array}$ & $\begin{array}{l}\text { male } \\
\text { speaker } \\
0-39\end{array}$ & $\begin{array}{l}\text { male } \\
\text { speaker } \\
40+\end{array}$ & total \\
\hline $\mathrm{AB}$ & $2,251,795$ & 949,735 & 779,228 & 868,907 & $4,849,665$ \\
\hline $\mathrm{C} 1 / \mathrm{C} 2$ & 590,270 & 319,492 & 541,014 & 236,276 & $1,687,052$ \\
\hline $\mathrm{DE}$ & $1,371,474$ & $1,258,595$ & $1,029,129$ & 830,689 & $4,489,887$ \\
\hline total & $4,213,539$ & $2,527,822$ & $2,349,371$ & $1,935,872$ & $11,026,604$ \\
\hline
\end{tabular}

Table 2: Subset sizes in the Spoken BNC2014 (number of tokens)

To extract all relevant occurrences of emotive interjections used discursively, the corpus was searched for Ow! and Ouch!, Ugh! and Yuck!, Whoops! and Whoopsadaisy!. Of course, spelling variants were considered. In total, eight separate queries were used (simple query, not case-sensitive): ow, ouch, whoops $s^{*}$ oops $s^{*}$ yuck, yuk, ugh, and urgh. Whoops $s^{*}$ and oops ${ }^{*}$ yield all relevant variants (e.g. Whoopsie!, Oops a daisy!, Whoopsy!, etc.). To date, it is impossible to select respondent restrictions in the Spoken BNC2014, so all conversations were considered (adult-adult and child-adult).

All hits that the query returned were extracted for analysis. Since the focus of this study is on the discursive use of emotive interjections, only discursive uses were considered in more detail. More precisely, everything else was discarded (stimulus-bound uses, reported speech, repetitions). Whenever Ugh!/Urgh! was used to express unnervedness (as in Example 9), this was classified as irrelevant, too (cf. Stange 2016a: 130). Naturally, this left only a fraction of the utterances extracted for analysis (see Table 3 below). 
(9) S0019: And I hate it when you're on the bus and they're on their mobile phone and it's I'm on the bus.

S0018: Mhm.

S0019: Urgh.

[SV2N: 60]

Discursive uses were identified as follows: a) by words like imagine, say or think in the immediate context, b) by people telling stories (past tense), c) by the obvious absence of a physical or sensory stimulus (for interjections of pain, any time there was no physical pain involved ${ }^{6}$; for spill cries if there was no actual mishap at the time of the utterance (Example 6 above); for interjections of disgust if there was no physical stimulus). Example 10 just below combines all three of these elements:

(10) S0585: [...] and she's like yeah I threw up through my nose and I was like no no. [...] So imagine sick ugh no.

S0587: Yeah and sick is so thick.

S0585: I know yeah.

S0587: Be able to like push it straight through.

S0585: Ugh ugh oh so horrible (pause) don't say that $u g h \mathrm{~mm}$.

[SNXG2302]

\section{Results \& Discussion}

\subsection{General - all interjections}

\subsubsection{Frequencies}

The Spoken BNC2014 contains a total of 771 occurrences of the emotive interjections under scrutiny. Of these occurrences, 140 are discursive uses - but these are spread out very unevenly across the six interjections (see Table 3).

\begin{tabular}{|l|r|r|r|r|r|}
\hline & \multicolumn{2}{|c|}{ frequency } & \multicolumn{3}{c|}{ of which discursive uses } \\
\hline interjection & raw & \multicolumn{1}{c|}{ pmw } & raw & pmw & percentage \\
\hline Ow! & 212 & $\mathbf{1 8 . 5 6}$ & 7 & $\mathbf{0 . 6 1}$ & 3.30 \\
\hline Ouch! & 59 & $\mathbf{5 . 1 7}$ & 12 & $\mathbf{1 . 0 5}$ & 20.34 \\
\hline Whoops! & 222 & $\mathbf{1 9 . 4 3}$ & 13 & $\mathbf{1 . 1 4}$ & 5.86 \\
\hline Whoopsadaisy! & 3 & $\mathbf{0 . 2 6}$ & 0 & $\mathbf{0}$ & 0 \\
\hline Yuck! & 46 & $\mathbf{4 . 0 3}$ & 13 & $\mathbf{1 . 1 4}$ & 28.26 \\
\hline Ugh! & 229 & $\mathbf{2 0 . 0 5}$ & 95 & $\mathbf{8 . 3 2}$ & 41.48 \\
\hline total & 771 & $\mathbf{6 7 . 5}$ & 140 & $\mathbf{1 2 . 2 6}$ & 18.16 \\
\hline
\end{tabular}

Table 3: Frequency of emotive interjections (Spoken BNC2014) 


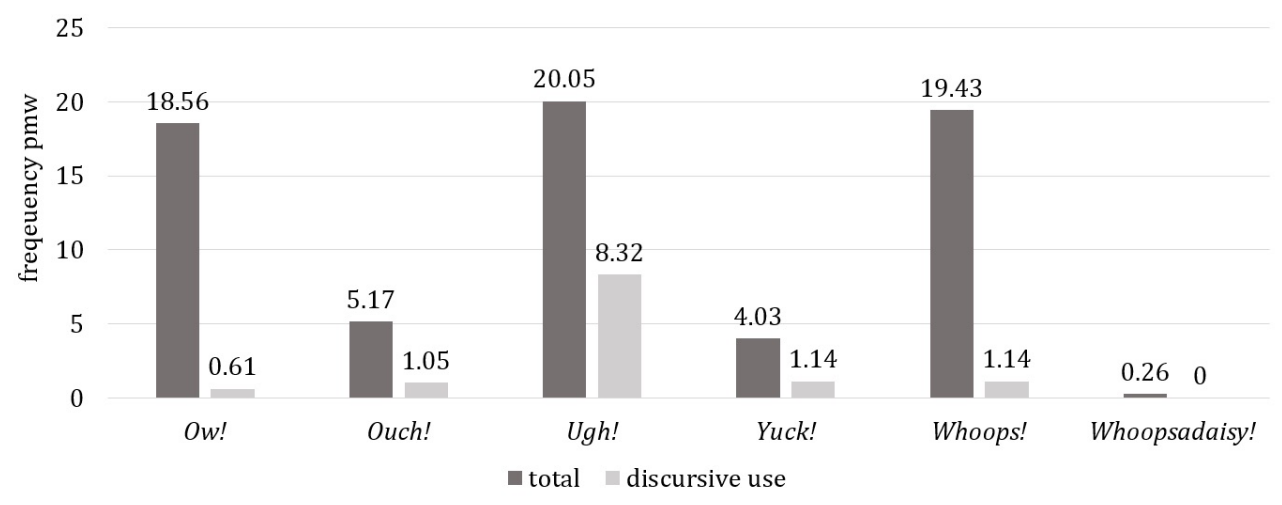

Figure 1: Emotive interjections in spoken British English (Spoken BNC2014)

Figure 1 visualises the frequencies per million words of emotive interjections as provided in Table 3. Ugh!, Whoops! and Ow! occur with similar frequencies in spoken British English (around 19 occurrences pmw), followed by Ouch! and Yuck! (also with similar frequencies around 4.5 occ. pmw) and Whoopsadaisy! (extremely rare with 0.26 occ. pmw). Interestingly, the interjections vary considerably with respect to how frequently they are used discursively: they range from 0 occ. pmw (Whoopsadaisy!) to 8 occ. pmw (Ugh!). The chi square test reveals that these differences are very highly significant $\left(p<0.001^{* * *}, \chi^{2}=140.84, \mathrm{df}=4^{7}\right)$. More specifically, the residuals show that both $O w$ ! and Whoops! occur significantly less frequently in discursive uses than expected, while the opposite is the case for Ugh!.

Figure 2 visualises how often an emotive interjection is used discursively with reference to all its occurrences. Ugh! is extremely frequent in discursive use: almost every other utterance we encounter in spoken English is used in this context (41 per cent of all utterances). Yuck! and Ouch!, too, are common in discursive uses (28 and 20 per cent, respectively). Whoops! and $O w !$, then, are occur almost exclusively with stimulus-bound uses and in reported speech ( 6 and 3 per cent of all occurrences can be attributed to discursive uses), while Whoopsadaisy! is not used discursively at all. The latter finding makes perfect sense for two reasons: 1) Whoopsadaisy! is an interjection that is restricted to child-adult interactions, but 2) discursive uses are absent from child speech and child-directed speech (cf. Stange 2016a: 203). 


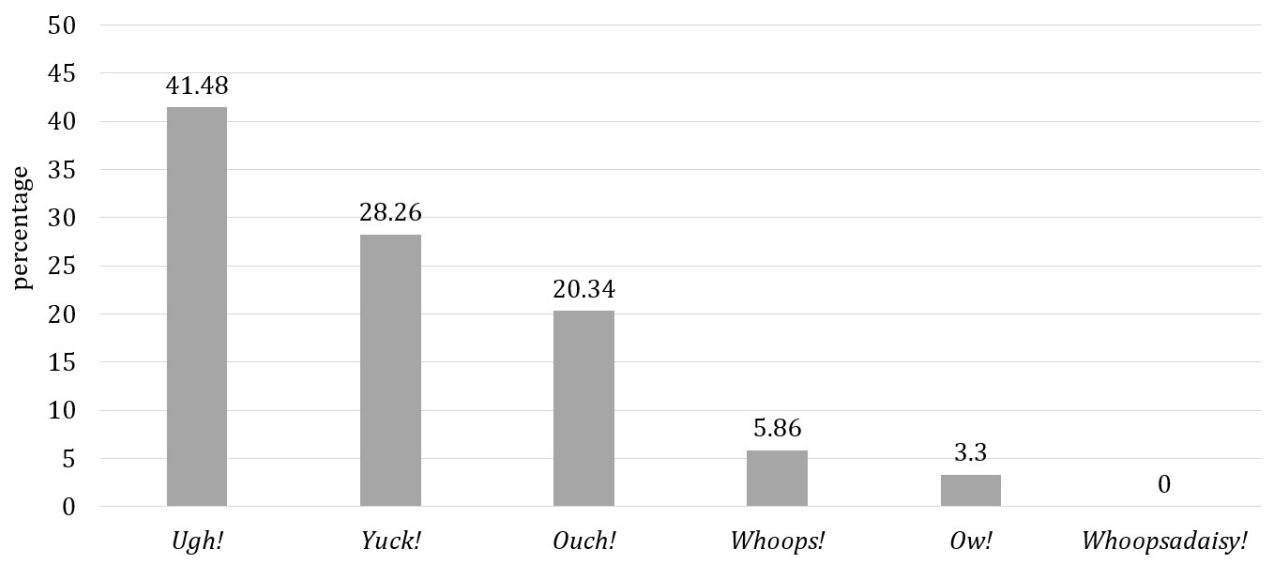

Figure 2: Proportion of discursive uses of emotive interjections (Spoken BNC2014)

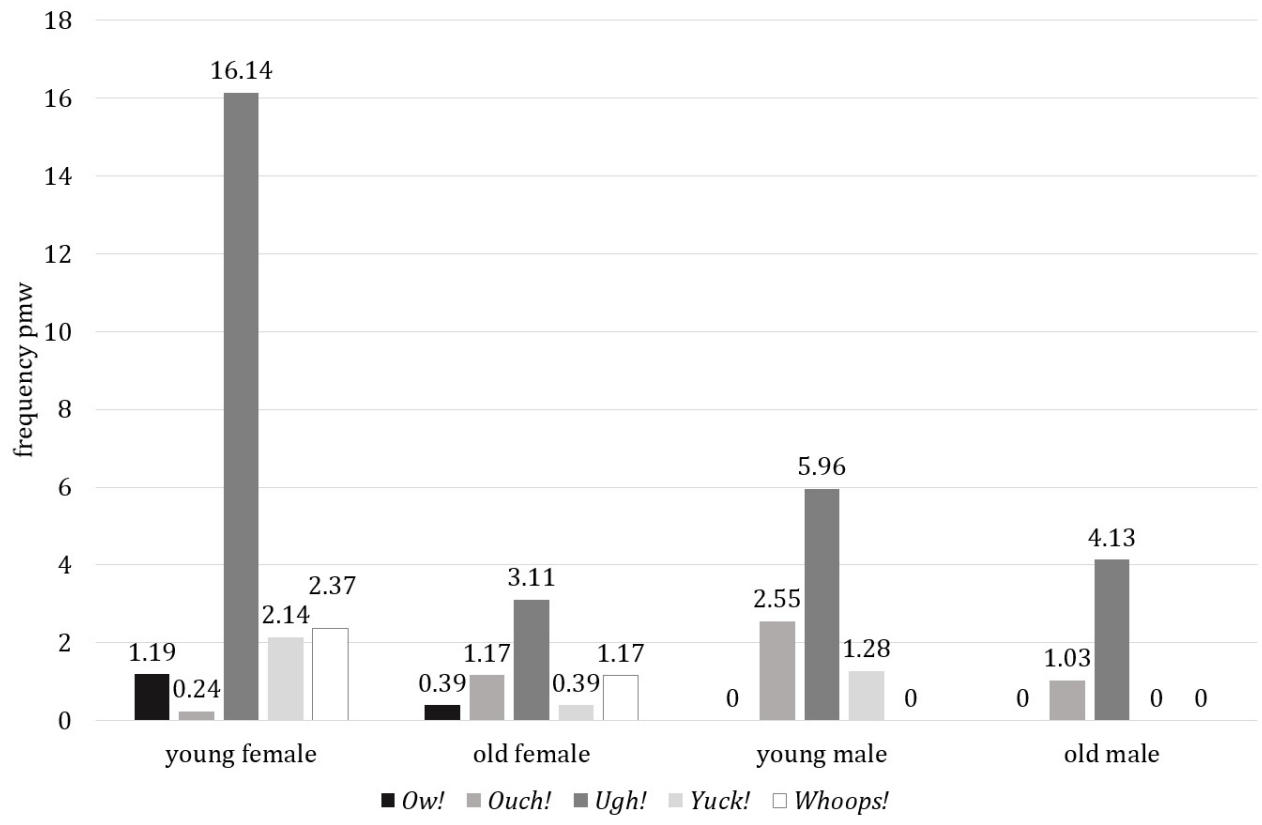

Figure 3: Discursive use of emotive interjections - distribution based on speaker age and gender (Spoken BNC2014)

\subsubsection{Speaker age and gender}

With respect to speaker age and gender, young female speakers are the ones who use emotive interjections discursively by far most frequently (total of 22.08 occ. pmw), followed by young male speakers (9.79 occ. pmw), old female speakers ( 6.23 occ. pmw), and finally, old male speakers (5.16 occ. pmw, see Figure 3). It is noteworthy that female speakers exhibit a wider range of emotive interjections in discursive use. All five interjections were found in their speech, while male speakers only use interjections of disgust and Ouch! (see Figure 3). These findings could indicate that female speakers display spontaneous emotions more readily in the form of interjections. 
Incidentally, previous studies on intensifiers have found that female speech is more emotionally coloured than male speech (cf. Tagliamonte \& Roberts 2005: 289). These findings, then, go perfectly well together. Of course, the number of tokens in this study is very small for all interjections except Ugh!, so these trends need to be verified with a larger, balanced data set.

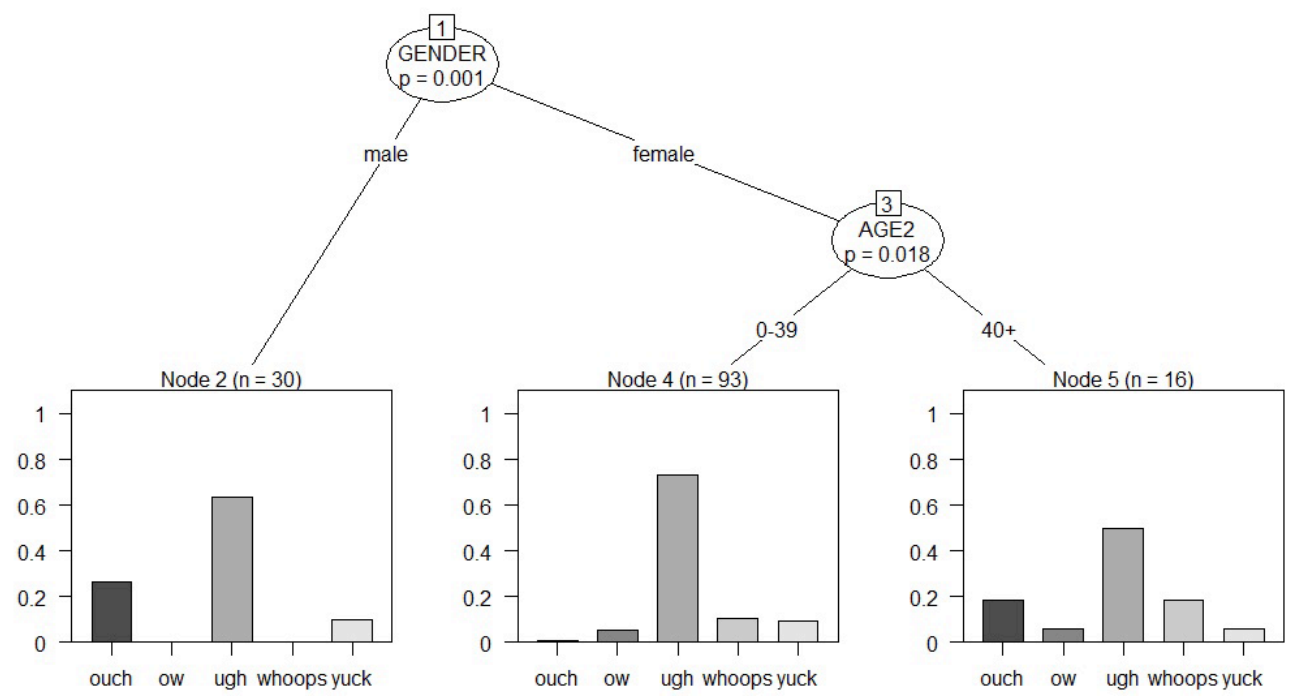

Figure 4: Discursive use of emotive interjections - factoring in speaker age and gender (Spoken BNC2014)

The conditional inference tree in Figure 4 shows that 1) there are significant differences between male and female speakers in the discursive use of emotive interjections $\left(p=0.001^{\star * *}\right)$, and that 2 ) young female speakers behave differently from old female speakers ( $p=0.018^{* *}$, accuracy of the model: 68.35 per cent). ${ }^{8}$ Thus, male speakers of any age use emotive interjections similarly (in that they only use Ugh!, Yuck! and Ouch!), while female speakers have varying preferences depending on how old they are. Young female speakers mainly use Ugh!, and there are next to no occurrences for the discursive use of Ouch!. Older female speakers, on the other hand, use Ouch! and Whoops! considerably more frequently. These findings indicate that both age and gender are relevant factors with respect to how frequently individual emotive interjections are used discursively. ${ }^{9}$

\subsubsection{Speaker social grade}

Regarding the socio-economic status of the speakers in question, statistical analyses reveal that it has no significant bearing on the discursive use of emotive interjections (decision tree analysis). Accordingly, the bars display similar distributional patterns for $\mathrm{AB}, \mathrm{C} 1 / \mathrm{C} 2$ and DE in Figure 5. 


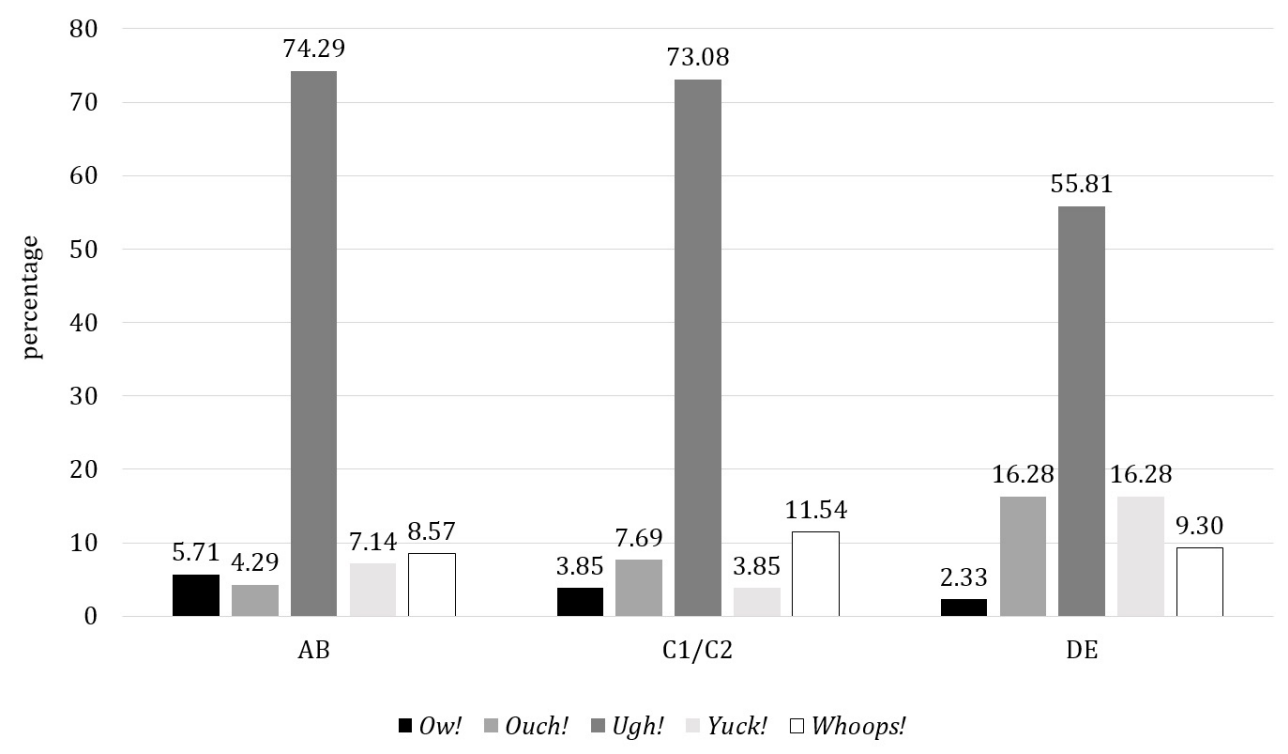

Figure 5: Discursive use of emotive interjections - distribution based on speaker social grade (Spoken BNC2014)

\subsubsection{Speaker dyad}

Next, we will turn to whether the type of dyad affects the discursive use of interjections. Figure 6 shows that the bars look very similar for male-male and male-female dyads. ${ }^{10}$ This is indicative of male speakers being unaffected by the gender of their conversational partner where the discursive use of interjections is concerned. Women, on the other hand, have different patterns: in same-sex conversations, Whoops! is the second most frequent interjection ( 16.13 occ. pmw), followed by $O w$ ! (6.45 occ. pmw) and Yuck! (4.84 occ. pmw). When they talk to a male person, on the other hand, the second most frequent interjection is Yuck! (14.89 occ. pmw), followed by Whoops! (6.38 occ. pmw). These findings suggest two things: 1) female speakers show support by using Whoops! to downplay import in dyads in general but more so in same-sex ones, while women are 2) apparently exposed to more revolting abstract stimuli when they engage in conversation with male speakers. 


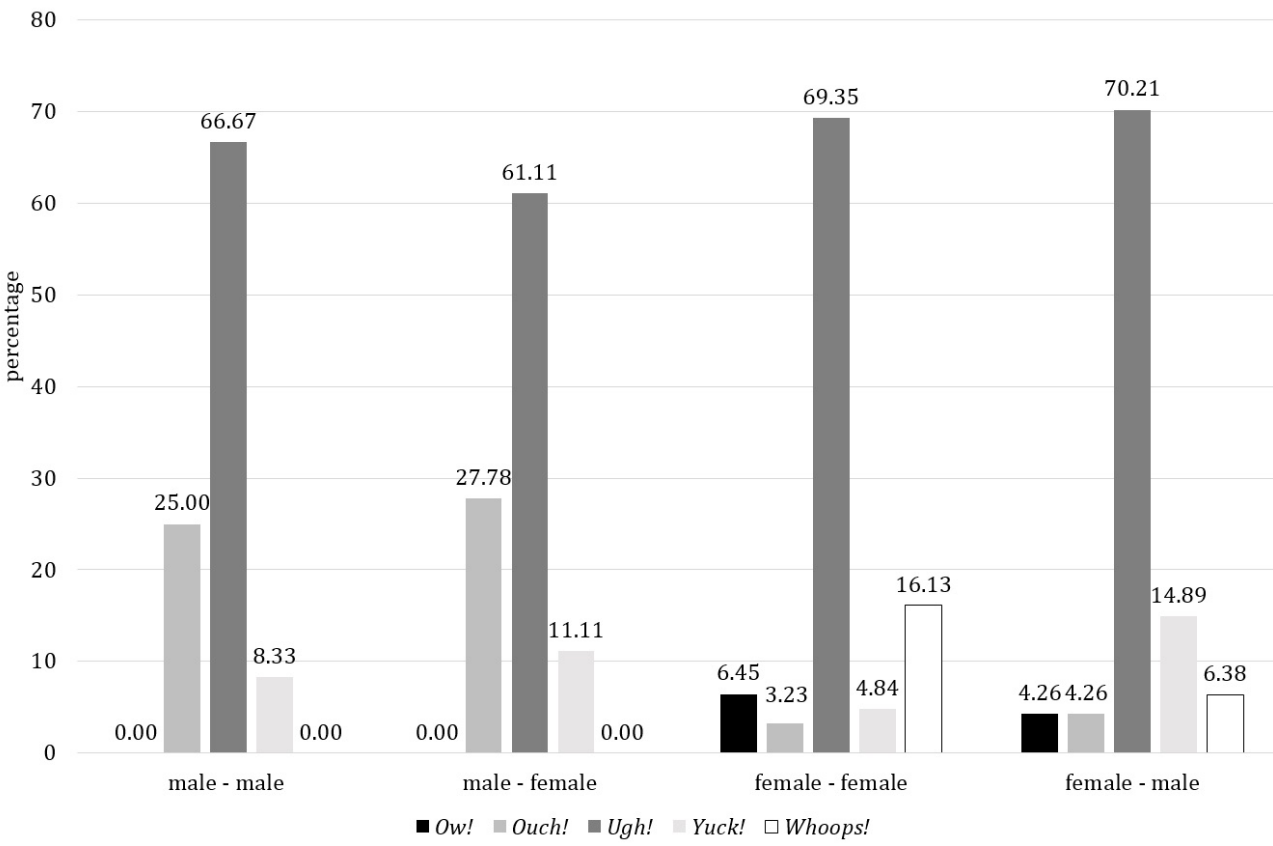

Figure 6: Discursive use of emotive interjections - distribution based on type of speaker dyad (Spoken BNC2014)

The decision tree analysis reveals that significant differences in speaker dyads can be grouped according to speaker gender: respondent gender is irrelevant ( $p=0.012^{\star \star}$, Figure 7). Distinguishing between different types of dyads is thus of no importance when discussing the discursive use of emotive interjections.

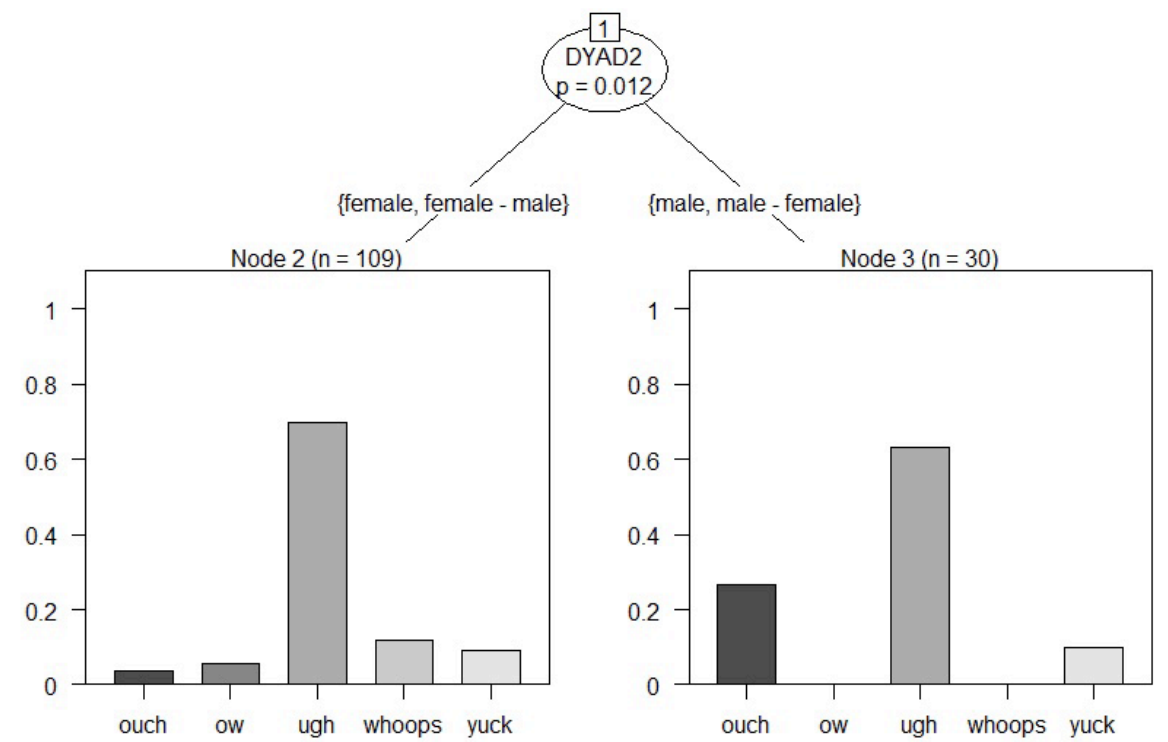

Figure 7: Discursive use of emotive interjections - factoring in type of speaker dyad (Spoken BNC2014) 
The following sections will zoom in on individual interjections and comment on interesting findings only.

\subsection{Specific Interjections}

\subsubsection{Interjections of pain}

There are a number of interesting observations on the discursive uses of $O w$ ! and Ouch!. First, although Ouch! is much rarer in spoken English than Ow! (5.17 vs. 18.56 occurrences pmw), it is found twice as frequently in discursive uses ( 1.05 vs. 0.61 occurrences pmw). Thus, discursive uses account for only 3.3 per cent of all occurrences of Ow!, while it is 20.34 per cent for Ouch!. This finding is in accordance with Ouch! being preferred in "other-oriented use[s]" (cf. Stange 2016a: 111).

Second, young female speakers are the only ones to prefer Ow! to Ouch! in discursive uses, and markedly so. Figure 8 shows that male speakers opt for Ouch! regardless of age, while old female speakers sometimes use $O w !$.

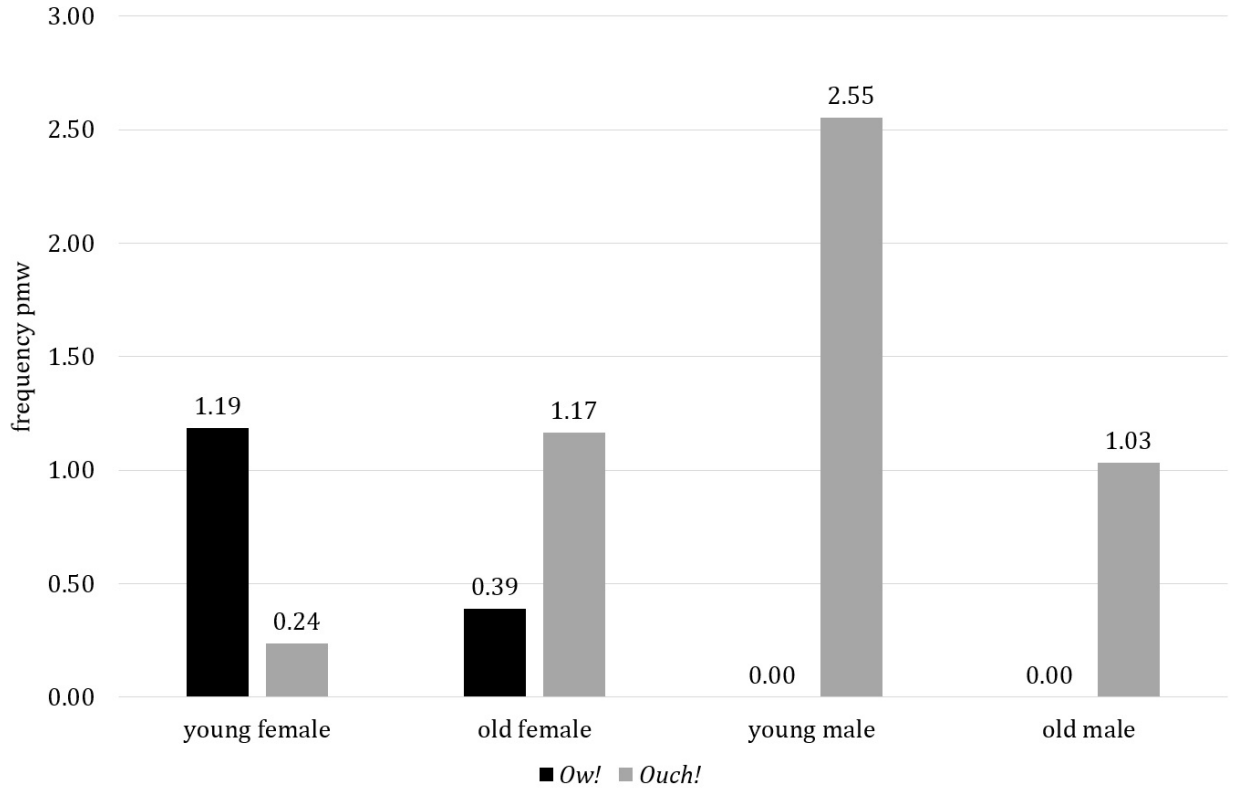

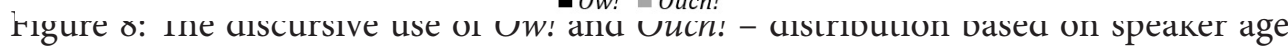
and gender (Spoken BNC2014)

Third, speakers of the social grades D and E strongly prefer Ouch! (87.5 per cent). This preference becomes less prominent for speakers of the social grades C1 and C2 (67 per cent), and is finally reversed for speakers of the social grades A and B (43 per cent Ouch!, see Figure 9).

Fourth, male speakers fail to use $O w$ ! discursively although they are exposed to it in mixed dyads (see Figure 6). However, since the number of tokens is quite small $\left(\mathrm{N}_{\text {total }}=19\right)$, all these trends need to be verified with a larger data set. 


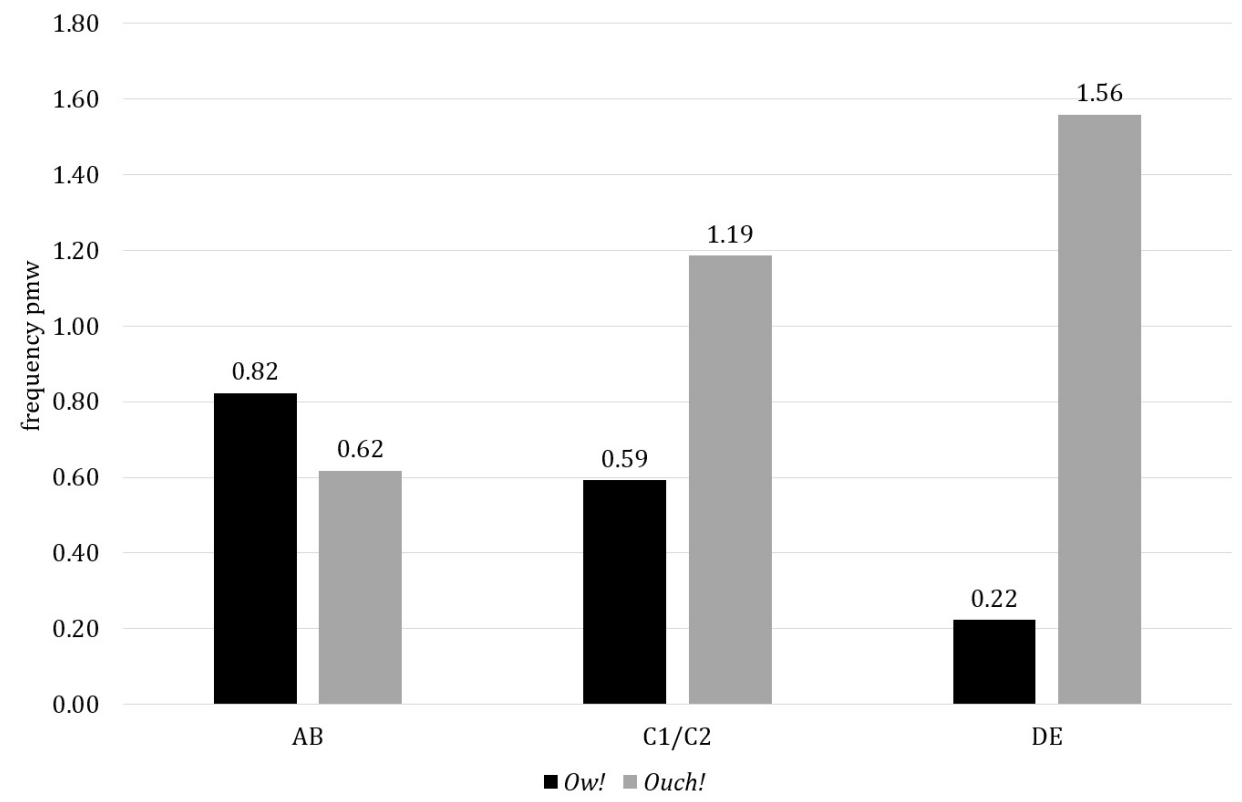

Figure 9: The discursive use of $O w !$ and Ouch! - distribution based on social grade (Spoken BNC2014)

\subsubsection{Interjections of disgust}

Where the discursive use of Ugh! and Yuck! is concerned, the former is always the preferred option, regardless of speaker age and gender (Figure 10). Possibly, this interjection (which imitates retching noises) is selected intuitively as more appropriate to signal an "authentic" sensation of disgust than arbitrary, lexicalised Yuck!.

As regards speaker social grade, $U g h$ ! is found twice as frequently with $\mathrm{AB}$ and $\mathrm{C} 1 / \mathrm{C} 2$ speakers than with $\mathrm{DE}$ speakers (approx. 11 occ. pmw vs. 5.4 occ. pmw). The latter, in turn, use Yuck! more frequently than the other speaker groups ( 1.6 occ. pmw vs. 1 occ. pmw (AB) vs. 0.6 occ. pmw (C1/ $\mathrm{C} 2$ ), see Figure 11). Looking at aggregate frequencies, $\mathrm{AB}$ and $\mathrm{C} 1 / \mathrm{C} 2$ speakers use interjections of disgust discursively almost twice as frequently compared to DE speakers (c. 12 occ. pmw vs. c. 7 occ. pmw). As the discursive use of Ugh! and Yuck! is an ostentatious display of disgust, this finding could suggest that upper and middle-class speakers are more sensitive to abstract revolting stimuli and maybe even exaggerate, while lower class speakers are tougher in a way. The distribution of Ugh! vs. Yuck! is not affected by the type of dyad (average ratio 9:1 for all dyads). 
Ulrike Stange

Scandinavian Studies in Language, 10(1), 2019 (174-193)

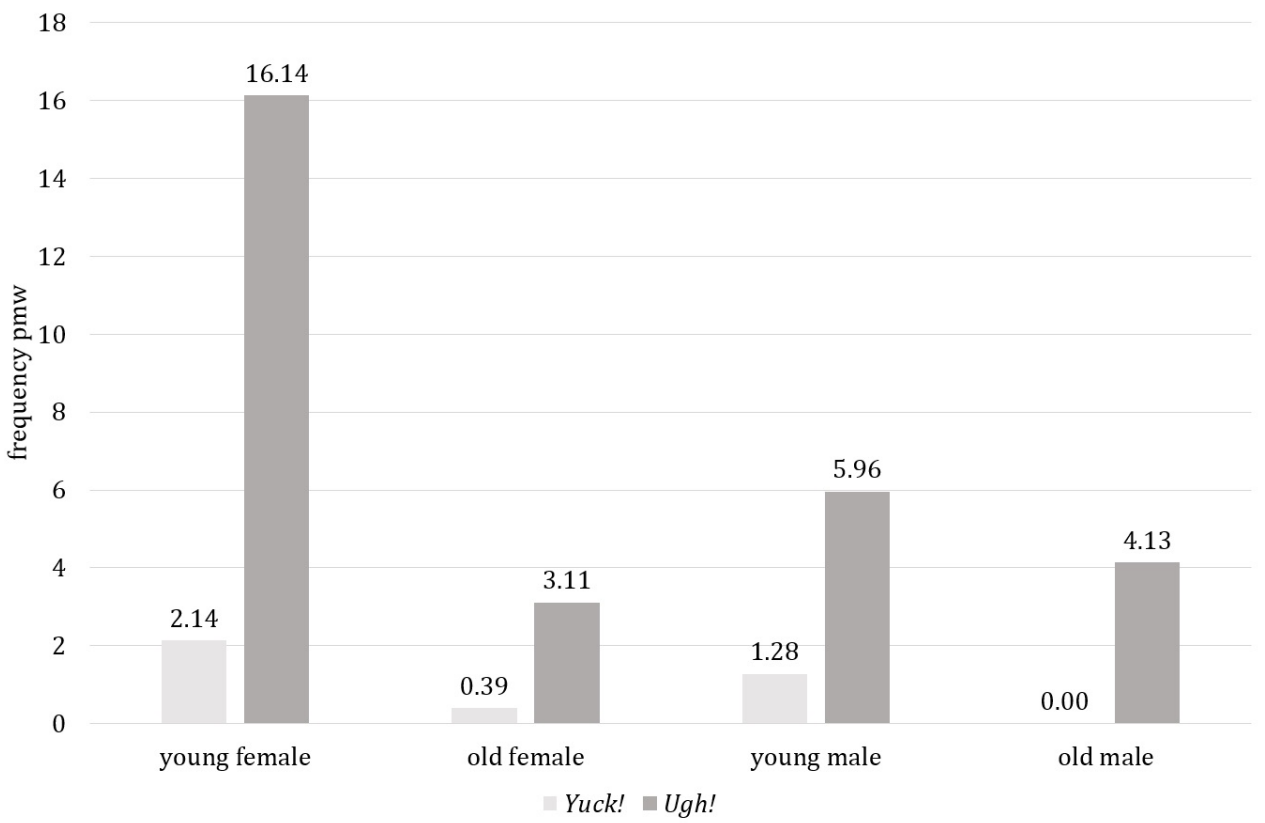

Figure 10: The discursive use of Ugh! and Yuck! - distribution based on speaker age and gender (Spoken BNC2014)

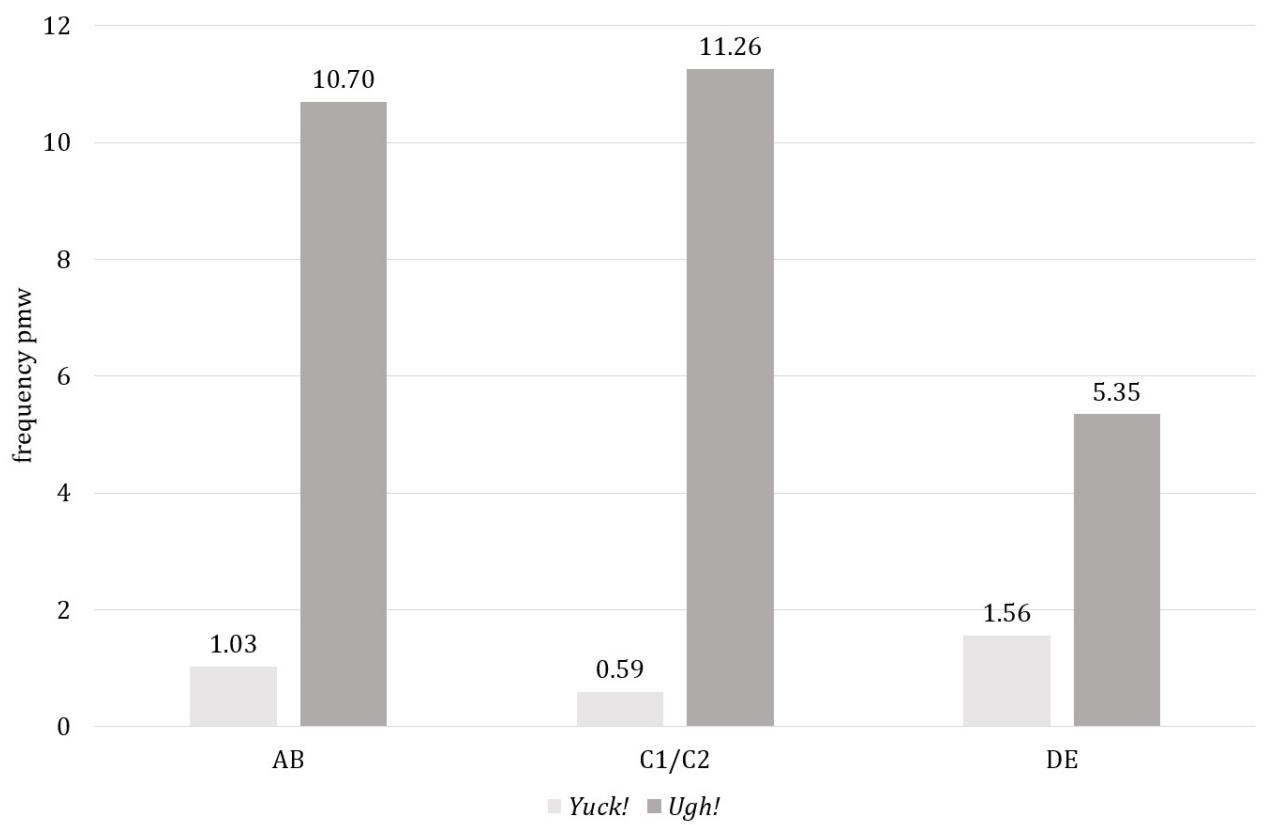

Figure 11: The discursive use of Ugh! and Yuck! - distribution based on social grade (Spoken BNC2014) 


\subsubsection{Spill cries}

There are several noteworthy observations on the discursive uses of Whoops! and Whoopsadaisy!. First, the latter is not attested in discursive uses, so there is no competition between these two spill cries in this respect. Second, although Whoops! is quite frequent in spoken English (19.43 occ. pmw), it is rarely used discursively (1.14 occ. pmw, see Table 3 ). Thus, discursive uses account for only 5.85 per cent of all occurrences of Whoops!. Third, male speakers fail to produce Whoops! in discursive uses, although they are exposed to this use in mixed dyads (see Figure 6 above). Moreover, Figure 12 shows that young female speakers produced Whoops! more frequently than older ones in the Spoken BNC2014. Last, Whoops! in discursive uses is found with female speakers of all social grades with similar frequencies of use (see Figure 5 above).

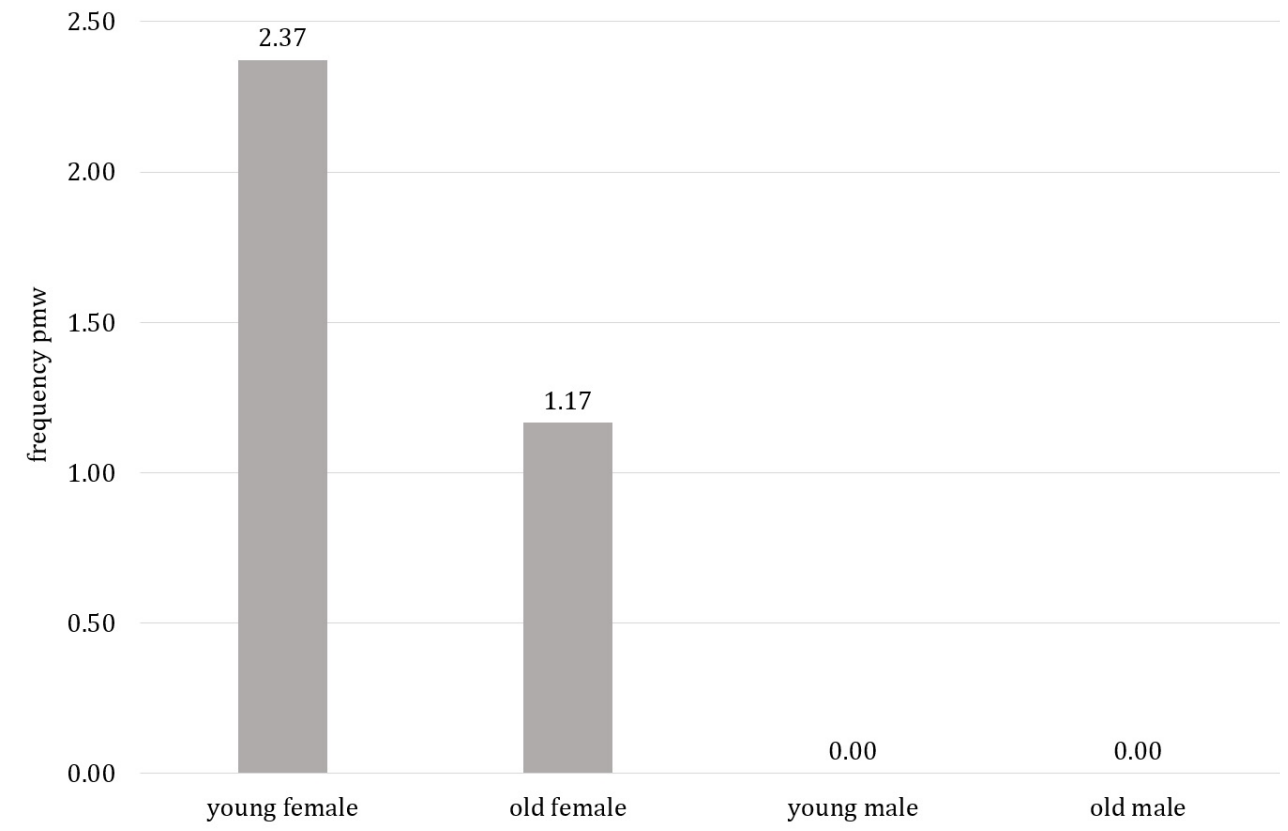

Figure 12: The discursive use of Whoops! - distribution based on speaker age and gender (Spoken BNC2014)

Before turning to the conclusion, it is important to stress that all results listed here indicate trends only, despite the significant $p$-values yielded by statistical analyses. The overall number of relevant tokens is only 140, two thirds of which can be attributed to Ugh!. Furthermore, the data are heavily skewed in that young female speakers $(\mathrm{AB})$ contribute 20 per cent, while old male speakers $(\mathrm{C} 1 / \mathrm{C} 2)$ account for only 2 per cent (with 12 different groups, 8-9 per cent per group would have resulted in a balanced data set). Notwithstanding these issues, this pilot study has identified potential social factors influencing the discursive use of emotive interjections. 


\section{Conclusion \& Outlook}

This exploratory small-scale study has offered first insights into the social life of emotive interjections in discursive uses. The relevant utterances were drawn from the Spoken BNC 2014 and coded for speaker age, gender and socio-economic status as well as type of dyad to explore potential factors governing the discursive use of the interjections Ow! and Ouch!, Whoops! and Whoopsadaisy!, as well as Ugh! and Yuck!. The study yielded several novel and interesting findings. 1) The individual interjections vary significantly regarding how frequently they are found in discursive uses $\left.\left(p<0.001^{\star * *}\right) .2\right)$ Whoopsadaisy! is not attested in discursive uses. 3) Young female speakers behave differently from the other speaker groups in that they use emotive interjections discursively significantly more frequently $\left(p=0.006^{* * *}\right)$. 4) Female speakers in general use a wider range of interjections discursively: Ow! and Whoops! in discursive uses were absent from male speech. 5) Socioeconomic status is irrelevant, as is 6) type of speaker dyad. Thus, the social life of emotive interjections is mainly influenced by speaker gender, and if they are female, also by their age.

Having said this, it is important to stress that the number of tokens the findings are based on is very small (140 in total), so all these results need to be verified with a larger, balanced data set. It should also be worthwhile to include other emotive interjections in future studies (e.g. Wow!, Oh! or Phew!). This pilot study has shown that there is still a lot to discover about interjections, and it will be interesting to see what else will be unveiled about them in future research.

\section{Acknowledgments}

I would like to offer my warmest thanks and heartfelt appreciation to Tina Thode Hougaard, Eva Skafte Jensen, Carsten Levisen and all contributors, who, with their passionate enthusiasm for interjections, have made this special issue possible. I would also like to thank the anonymous reviewer for their constructive and valuable comments on an earlier version of this paper. Naturally, any errors remaining are entirely my own.

\section{Notes}

1 The transcripts were altered slightly in terms of format to enhance legibility. Changes include the insertion of random names for anonymised names, punctuation and capitalisation.

2 This term is borrowed from Goffman (1978) because it is perceived as more adequate than interjections of surprise.

3 Unless indicated otherwise, all examples are taken from the Spoken BNC20144 The manual is available at http://corpora.lancs.ac.uk/bnc2014/documentation. php. 
5 AB: Higher managerial, administrative and professional; intermediate managerial, administrative and professional;

C1/C2: Supervisory, clerical and junior managerial, administrative and professiona; skilled manual workers;

DE: Semi-skilled and unskilled manual workers; state pensioners, casual and lowest grade workers, unemployed with state benefits only (extract from the BNC2014 manual).

6 NB: The use of Ow! and Ouch! to refer to anticipated or imaginary pain (as in pretend play with children) classifies as stimulus-bound use if triggered by the immediate context.

7 Chi square test based on observed frequencies for Ow!, Ouch!, Whoops!, Ugh! and Yuck! in discursive vs. non-discursive uses.

8 All conditional inference trees were created in RStudio using the function ctree in the add-on package party.

9 If the variables age and gender are combined, the same statistical test yields that young female speakers behave significantly different from all other speaker groups $\left(p=0.006^{* * *}\right)$.

${ }^{10}$ First item in a pair: gender of the person using the interjection. Second item: respondent/conversational partner.

\section{References}

BNC1990 British National Corpus, available at:

https://cqpweb.lancs.ac.uk/bncxmlweb/

BNC2014 British National Corpus, available at:

https://cqpweb.lancs.ac.uk/bnc2014spoken/

Ameka, Felix (1992). Interjections: The universal yet neglected part of speech, Journal of Pragmatics, vol. 18.2, 101-118.

Goddard, Cliff (2014a). On 'disgust', in: Balder, Fabienne and Georgeta Cislaru (eds.), Linguistic Approaches to Emotions in Context, John Benjamins.

Goddard, Cliff (2014b). Interjections and emotion (with special reference to "surprise" and "disgust"), Emotion Review, vol. 6, 53-63.

Goffman, Erving (1978). Response cries, Language, vol. 54, 787-815.

Love, Robbie; Dembry, Claire; Hardie, Aandrew; Brezina, Vaclav \& McEnery, Tony (2017). The Spoken BNC2014: designing and building a spoken corpus of everyday conversations, International Journal of Corpus Linguistics, vol. 22, 319-344.

Love, Robbie; Hawtin, Abi \& Andrew Hardie (2017). The British National Corpus 2014: User Manual and Reference Guide. Cambridge University Press. http://corpora.lancs.ac.uk/bnc2014/documentation.php

Norrick, Neal R. (2011). Interjections, in: Gisle Andersen \& Karin Aijmer (eds.), Pragmatics of Society, De Gruyter Mouton.

Nübling, Damaris (2001). Von oh mein Jesus! zu oje! - Der Interjektionalisierungspfad von der sekundären zur primären Interjektion, Deutsche Sprache, vol. 29, 20-45.

Nübling, Damaris (2004). Die prototypische Interjektion: Ein Definitionsvorschlag, Zeitschrift für Semiotik, vol. 26, 11-46. 
Rosenbach, Anette (2003). Iconicity and economy in the choice between the 's-genitive and the of-genitive, in: Rohdenburg, Günter und Britta Mondorf (eds.), Determinants of Grammatical Variation in English, Mouton de Gruyter.

Stange, Ulrike (2009). The Acquisition of Interjections in Early Childhood, Diplomica.

Stange, Ulrike (2016a). Emotive Interjections in British English: A Corpus-Based Study on Variation in Acquisition, Function and Usage, John Benjamins.

Stange, Ulrike (2016b). I was sat there talking all night: A corpus-based study on factors governing intra-dialectal variation in British English, English Language and Linguistics, vol. 20,511-531.

Tagliamonte, Sali \& Chris Roberts (2005). So weird; so cool; so innovative: The use of intensifiers in the television series Friends, American Speech, vol. 80, 280-300.

Wierzbicka, Anna (1992). The semantics of interjection, Journal of Pragmatics, vol. 18, 159-192.

Wilkins, David P. (1992). Interjections as deictics, Journal of Pragmatics, vol. 18, 119158. 